\title{
Efeito da Densidade de Tubérculos de TiRiRica (Cyperus rotundus) Sobre o Crescimento Inicial de Plantas de Algodão'
}

\author{
Effect of Purple Nutsedge (Cyperus rotundus) Tuber Density on the Initial Growth of \\ Cotton Plants
}

\author{
SALGADO, T.P. ${ }^{2}$, ALVES, P.L.C.A. ${ }^{3}$ e ROSSI, C.V.S. ${ }^{4}$
}

\begin{abstract}
RESUMO - O objetivo deste trabalho foi avaliar a interferência de densidades de tubérculos de tiririca no crescimento inicial de plantas de algodão, cultivar Delta Opal. Para isso, utilizaram-se caixas de cimento-amianto $(0,60 \times 0,60 \times 0,25 \mathrm{~m})$ com Latossolo Vermelho Escuro, no centro das quais foram semeadas seis sementes de algodão, em linha, espaçadas de $0,10 \mathrm{~m}$; em seguida, plantaram-se tubérculos de tiririca nas densidades de $0,5,10,15$, $25,50,75,100,125,150,175$ e 200 tubérculos por caixa, que foram nestas distribuídos aleatoriamente. O delineamento experimental foi o de blocos casualizados, em quatro repetições. Aos 50 dias após a semeadura, foram determinados, nas plantas de algodão, a altura e o teor relativo de clorofila total. Ao término do período experimental (65 dias após a emergência do algodão), foram determinados: altura, teor relativo de clorofila total, área foliar e matéria seca do caule e das folhas. Nas plantas de tiririca foi feita a contagem do número final de plantas (partes aéreas) por caixa. A interferência da tiririca no crescimento inicial do algodoeiro iniciou-se a partir de 5 tubérculos/caixa, reduzindo em até $71 \%$ as características analisadas na mais alta densidade (200 tubérculos/caixa). A competição intraespecífica na tiririca acentuou-se a partir de 75 tubérculos/caixa, quando obteve mais do que 1,86 brotação por tubérculo. As características avaliadas nas plantas de algodão mais sensíveis ao efeito dos tubérculos de tiririca foram: área foliar, massa seca de folhas, caule e altura das plantas, nesta ordem.
\end{abstract}

Palavras-chave: plantas daninhas, interferência, desenvolvimento, área foliar.

\begin{abstract}
The aim of this research was to evaluate the effect of purple nutsedge (Cyperus rotundus) tuber density on the initial growth of cotton (Gossypium hirsutum) plants, cultivar Delta Opal. Boxes $(0.60 \times 0.60 \times 0.25 \mathrm{~m})$ containing red Latosol were used as recipients, where six cotton seeds were seeded in the center of the boxes spaced by $0.10 \mathrm{~m}$; followed by the purple nutsedge tuber density in the boxes $(0,5,10,15,25,50,75,100,125,150,175$, 200 tubers per box), planted randomly. The experiment was arranged in a randomized complete block design with four replications. Height and the total chlorophyll content were determined 50 days after cotton seeding. At the end of the experiment (65 days after cotton emergence), height, total relative chlorophyll content, leaf area and dry weight of shoots and leaves were determined. The final number of shoots per box was evaluated in the purple nutsedge plants. The interference of the purple nutsedge in the initial growth of cotton initiated with 5 tubers/ box, reducing up to $71 \%$ of the characteristics analyzed under the highest density (200 tubers/ box). The intra specific competition was more intense in 75 tubers/box, when over 1.86 sprouts per tuber were obtained. The cotton characteristics most sensitive to the interference of purple nutsedge were: leaf area, leaf dry matter and plant stem and height.
\end{abstract}

Key words: weed, interference, development, leaf area.

Recebido para publicação em 14/5/2002 e na forma revisada em 9/12/2002.

2 Mestrando no Programa de Produção Vegetal da FCAV-UNESP, Jaboticabal-SP, <tpsalgado@ hotmail.com>; ${ }^{3}$ Eng.Agr., Professor Assistente Doutor do DBAA/FCAV-UNESP. Rod. Prof. Paulo Donato Castellane, s/n, 14884-900 Jaboticabal-SP, <plalves@fcav.unesp.br>; ${ }^{4}$ Mestrando no programa de Proteção de Plantas da FCA-UNESP, Fazenda Experimental do Lageado s/n. Dep. de Defesa Fitossanitária, 18603-970 Botucatu-SP, <cavsr@fca.unesp.br>.

Planta Daninha, Viçosa-MG, v.20, n.3, p.405-411, 2002 


\section{INTRODUÇÃO}

O algodoeiro herbáceo (Gossypium hirsutum) é uma das principais culturas exploradas no Brasil, sendo cultivada em 15 estados. Os vários segmentos envolvidos direta ou indiretamente com a cotonicultura representam cerca de $15 \%$ da economia nacional, o que reflete a importância dessa malvácea na agricultura (Beltrão \& Azevedo, 1994). A cotonicultura nacional passou por sérias dificuldades na década de 90 devido ao processo de abertura das fronteiras comerciais, o que proporcionou a entrada de produtos estrangeiros com menor custo de produção, refletindo em diminuição drástica na área cultivada na safra 1996/1997. Atualmente os valores se inverteram, e o algodoeiro é a cultura anual que permite as maiores taxas de retorno econômico, ainda que ofereça maiores riscos e demande alto nível técnico (Agrianual, 2001).

A lavoura do algodoeiro deve ser conduzida para atingir os seus mais altos niveis potenciais de produtividade e qualidade. Nesse contexto, devemos considerar o manejo de plantas daninhas, o qual deve estar inserido no planejamento da lavoura como um todo, e o conhecimento prévio do potencial de infestação (espécies e níveis de ocorrência) é premissa fundamental para se obter êxito. Dessa forma, é indispensável que haja levantamentos e monitoramentos preliminares nas áreas que são ou serão cultivadas (Laca-Buendia, 1992; Cia et al., 1999).

O grau de interferência das plantas daninhas sobre culturas agrícolas se deve a diversos fatores ligados à comunidade infestante (composição específica, densidade e distribuição), à cultura (espécie, espaçamento e densidade de plantio), ao ambiente (condições edáficas, climáticas e tratos culturais) e ao período de convivência de ambos (Bleasdale, 1960; Blanco, 1972; Pitelli, 1985).

Por apresentar crescimento inicial lento (Azevedo et al., 1993), metabolismo fotossintético típico de plantas $\mathrm{C}_{3}$ (Benedict, 1984) e raízes superficiais (Freire \& Alves, 1976; Oliveira \& Silva, 1987), o que deixa a planta mais vulnerável à competição e aos cultivos mecânicos, o algodoeiro é considerado uma planta altamente sensivel à interferência das plantas daninhas (Beltrão \& Azevedo, 1994).
A convivência das plantas de algodão e das plantas infestantes durante todo o ciclo da cultura pode acarretar reduções que variam de 68 a 95\% na produtividade, sem contar os inconvenientes na colheita (Cia et al., 1999).

Segundo Forster \& Paulo (1984), as gramíneas já iniciam o seu prejuízo à produção se conviverem com o algodão por um período de 10 a 20 dias. As dicotiledôneas, por sua vez, iniciam redução na produção após sua permanência junto à cultura por um período entre 20 e 30 dias a contar da emergência do algodão.

No caso da tiririca (Cyperus rotundus), Blanco et al. (1991) verificaram que populações que emergem do solo após seis semanas do plantio do algodoeiro não causam prejuízos à planta cultivada.

A densidade de plantas daninhas é um dos fatores mais importantes, uma vez que, quanto maior ela for, maior será a quantidade de indivíduos que disputam os mesmos recursos do meio e, portanto, mais intensa será a competição sofrida pela cultura (Christoffoleti \& Victoria Filho, 1996).

Moffett \& McCloskey (1998) estudaram a interação entre umidade do solo e densidade de tubérculos de Cyperus esculentus durante três anos consecutivos (1993 a 1995) e seus efeitos na cultura do algodão. Por meio de análise de regressões lineares, estimaram reduções de 9 (1993), 12 (1994) e $37 \mathrm{~kg} \mathrm{ha}^{-1}$ (1995) de sementes em função do aumento do número de tubérculos.

Vencill et al. (1992) estudaram dois anos consecutivos a interferência do Cynodon dactylon sobre a cultura do algodão plantado no sistema de plantio direto e puderam estabelecer que, para cada $1.000 \mathrm{~kg} \mathrm{ha}^{-1}$ de matéria seca acumulada pela planta daninha, há de se esperar redução de $10 \%$ na produção de sementes de algodão. Em densidades elevadas dessa planta daninha houve redução de 16\% na altura das plantas na quinta semana, de $38 \%$ no índice de área foliar e de $25 \%$ na produção de sementes.

Bararpour et al. (1994), estudando os efeitos da convivência entre a cultura de algodão e a planta daninha Euphorbia maculata, constataram correlação linear significativa, indicando redução em altura, área foliar, peso de 
matéria seca, número de maçãs e produção de sementes de algodão em função do aumento da densidade da planta daninha. Com relação à produção de sementes, as reduções foram na ordem de 47, 57 e $85 \%$ para densidades de 5,10 e 50 plantas por metro de linha de plantio. Morgan et al. (2001) estudaram a competição interespecífica entre plantas de algodão e Amaranthus palmeri e decréscimo linear de 13 para 54\% de redução na produção de algodão devido a uma variação na densidade da planta daninha, que foi de 1 para 10 plantas/ 9,1 metros lineares.

Keeley \& Thullen (1991), estudando a variedade de algodão Acala SJ-2 sob o aspecto da matocompetição com Echinochloa crus-galli, verificaram que a convivência por um período de três semanas no início de desenvolvimento da cultura não afetou a produção. A convivência por 6, 9, 12 e 25 semanas resultou em perdas significativas de produção: $21,59,90$ e $97 \%$, respectivamente. No entanto, foram necessárias nove semanas de desenvolvimento livre da convivência com a planta daninha para minimizar as perdas de produção.

De acordo com Pitelli (1985), a existência do fenômeno alelopático é de grande importância na determinação do balanço da interferência da cultura-comunidade infestante. No estudo das relações de interferência entre o algodoeiro e a tiririca, as informações sobre os efeitos da densidade são escassas. Em razão disso, este trabalho objetivou estudar o efeito da interferência da tiririca (Cyperus rotundus), em densidades crescentes, no crescimento inicial do algodão (Gossypium hirsutum) cultivar Delta Opal.

\section{MATERIAL E MÉTODOS}

O trabalho foi conduzido sob condições semicontroladas (sem restrição de água), em área experimental pertencente ao Departamento de Biologia Aplicada à Agropecuária, FCAV - UNESP, campus de Jaboticabal.

Como recipientes foram utilizadas caixas de cimento-amianto $(0,60 \times 0,60 \times 0,25 \mathrm{~m})$, que foram preenchidas com Latossolo VermelhoEscuro (LV) (EMBRAPA, 1999), coletado na camada arável $(0-20 \mathrm{~cm})$. Deste solo foi retirada uma amostra composta de solo para análise química de rotina e de micronutrientes. Com base nos resultados da análise, foi feita a correção prévia da acidez do solo 40 dias antes do plantio, utilizando calcário dolomítico. Foram plantadas seis sementes de algodão (Gossypium hirsutum) cultivar Delta Opal, em linha, no centro das caixas, espaçadas em $10 \mathrm{~cm}$ entre si. Na ocasião do plantio, foi feita a correção da fertilidade do solo. Tanto a calagem quanto a adubação de plantio foram feitas com base em recomendações de Raij et al. (1997).

Por ocasião da semeadura do algodão, foram plantados $0,5,10,15,25,50,75,100,125$, 150,175 e 200 tubérculos de tiririca aleatoriamente por caixa, que constituíram os tratamentos experimentais. O delineamento experimental foi o de blocos ao acaso, com os 12 tratamentos (densidades) em quatro repetições.

Aos 50 dias após a semeadura, nas plantas de algodão foram avaliados a altura (pelo comprimento do caule principal) e o teor relativo de clorofila total (Minolta, mod. SPAD 502). Ao término do período experimental - 65 dias após a semeadura - foram determinados nas plantas de algodão: altura, teor relativo de clorofila total, área foliar (Li-Cor, mod. 3000A) e matéria seca do caule e das folhas (após secagem em estufa com circulação forçada de ar a $70{ }^{\circ} \mathrm{C}$ por pelo menos 96 horas). Nas plantas de tiririca foi feita a contagem do número final de plantas (partes aéreas) por caixa.

Os dados obtidos foram submetidos à análise de regressão com o programa Table Curves 2D (Jandel Scientific). A equação que apresentou maior coeficiente de determinação foi a exponencial do tipo $\mathrm{y}=\mathrm{a}+\mathrm{b} \exp ^{(-\mathrm{x} / \mathrm{c})}$, em que "a" refere-se ao valor mínimo, e praticamente estável, da característica avaliada nas plantas à medida que a densidade (x) aumenta e 1/c é a taxa de decréscimo ou acréscimo na característica em resposta às densidades.

Com base no número final de partes aéreas de tiririca e no número inicial de tubérculos plantados, calculou-se o número de brotações por tubérculos, correlacionando-o com a porcentagem de redução nas características analisadas nas plantas de algodão. A equação que apresentou maior coeficiente de determinação foi o modelo sigmoidal de Boltzman, e sua interpretação seguiu o procedimento descrito por Kuva et al. (2000).

Planta Daninha, Viçosa-MG, v.20, n.3, p.405-411, 2002 


\section{RESULTADOS E DISCUSSÃO}

A altura determinada das plantas de algodão foi de aproximadamente $27 \mathrm{~cm}$ nas parcelas testemunhas aos 50 e 65 dias após a semeadura, decrescendo com o aumento da densidade de tubérculos de tiririca até os 75 tubérculos / caixa $\left(0,36 \mathrm{~m}^{2}\right)$, após os quais tendeu a se estabilizar em aproximadamente $16 \mathrm{~cm}$ (Figuras 1 e 3). A redução da altura das plantas de algodão em resposta aos tratamentos (densidade de plantas) obedeceu a uma equação exponencial do tipo $\mathrm{y}=\mathrm{a}+\mathrm{bexp} \mathrm{e}^{(-\mathrm{x} / \mathrm{cc})}$, com constante de decréscimo de $\mathrm{x} / 31,30$ e $\mathrm{x} / 34,74$ aos 50 e $65 \mathrm{DAE}$, respectivamente. Os resultados demonstraram que, num intervalo de 15 dias entre as avaliações, as plantas de algodão não cresceram em altura.

Ainda aos 50 DAE, não se constatou efeito da densidade de tubérculos de tiririca sobre o teor relativo de clorofila total, que se manteve com um valor praticamente constante: 36,1 UR (Figura 2).

Blanco et al. (1991), analisando a interferência da tiririca na cultura de algodão, relataram que, quanto maior o número de tubérculos por área, menores foram os pesos das matérias fresca e seca das maçãs, folhas, caule e a altura das plantas de algodão. Os mesmos autores verificaram que densidades populacionais a partir de um tubérculo por $0,141 \mathrm{~m}^{2}$ provocam diminuições significativas e lineares no desenvolvimento e na produção dessa planta.

Com relação à área foliar das plantas de algodão (Figura 4), constatou-se decréscimo com o aumento da densidade de tubérculos de tiririca até os 75 tubérculos/caixa, após o que houve tendência de estabilização em aproximadamente $80,0 \mathrm{~cm}^{2}$. A partir da densidade de 5 tubérculos/caixa, houve redução significativa nesta característica. A equação utilizada seguiu o modelo exponencial, com uma constante de decréscimo de $\mathrm{x} / 29,95$.

No que se refere à matéria seca do caule (Figura 5) e das folhas (Figura 6), o efeito da densidade de tubérculos seguiu uma equação exponencial, com uma constante de decréscimo de $\mathrm{x} / 25,63$ para o caule e de $\mathrm{x} / 30,70$ para as folhas, com o minimo de aproximadamente 4,2 e 3,8 gramas para matéria seca de caule e folhas, respectivamente, seguindo o mesmo comportamento observado nas demais características. O efeito da densidade dos tubérculos tendeu a se estabilizar em 75 tubérculos/caixa. Para a matéria seca do caule, houve efeito significativo da densidade a partir dos 25 tubérculos/caixa, enquanto para a matéria seca das folhas esse efeito iniciou-se aos 5 tubérculos/ caixa.

Com relação ao teor relativo de clorofila total, verificou-se que o aumento na densidade de tubérculos de tiririca reduziu linearmente seu conteúdo relativo (Figura 7). De acordo com a equação obtida $(y=31,62-0,02 x)$, cada tubérculo acrescentado à caixa $\left(0,36 \mathrm{~m}^{2}\right)$ reduziu em 0,02 unidade relativa o teor relativo de clorofila total inicial de 31,6 unidades relativas obtido nas plantas das parcelas testemunhas.

Na Figura 8, observa-se que, à medida que aumentou o número de tubérculos nas caixas, houve menor taxa de brotação por tubérculo. Na menor densidade (5 tubérculos/caixa) verificaram-se 3,7 brotações por tubérculo, enquanto na maior densidade (200 tubérculos/ caixa) observou-se 1,1 brotação por tubérculo.

A estabilização do efeito negativo dos tubérculos de tiririca nas plantas de algodão a partir da densidade de 75 tubérculos/caixa correspondeu a 1,7 brotação por tubérculo e deve-se a um provável aumento na interferência intraespecífica, amenizando os efeitos da interespecífica. Segundo Solomon (1980), o crescimento populacional não pode continuar indefinidamente. À medida que o habitat se torna superpovoado ou que a exploração de algum requisito essencial se torne cada vez mais próxima do término, a taxa de crescimento deve diminuir até que o número de indivíduos atinja um ponto de saturação a partir do qual nenhum aumento posterior seja possível.

Outra possível explicação para os resultados está relacionada ao efeito alelopático causado pelas plantas de tiririca e/ou à interação entre aumento de densidade e efeito alelopático, como observado por Meissner et al. (1977) e Friedman \& Horowits (1971) para várias culturas. À proporção que se aumenta a densidade das espécies, maior é o efeito alelopático, provocando redução de crescimento e desenvolvimento tanto nas plantas de algodão quanto nas de tiririca. 


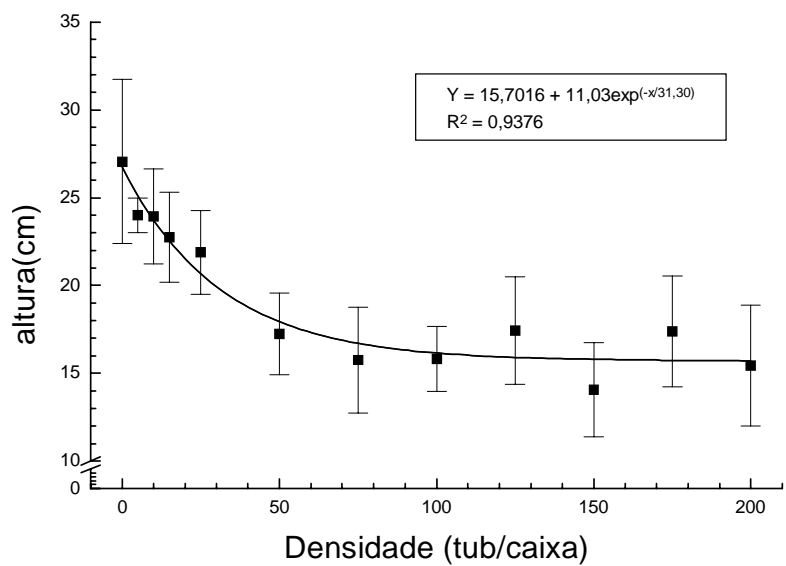

Figura 1 - Efeito da densidade de tubérculos de tiririca na altura das plantas de algodão aos 50 dias após a semeadura. Jaboticabal-SP, 2001.

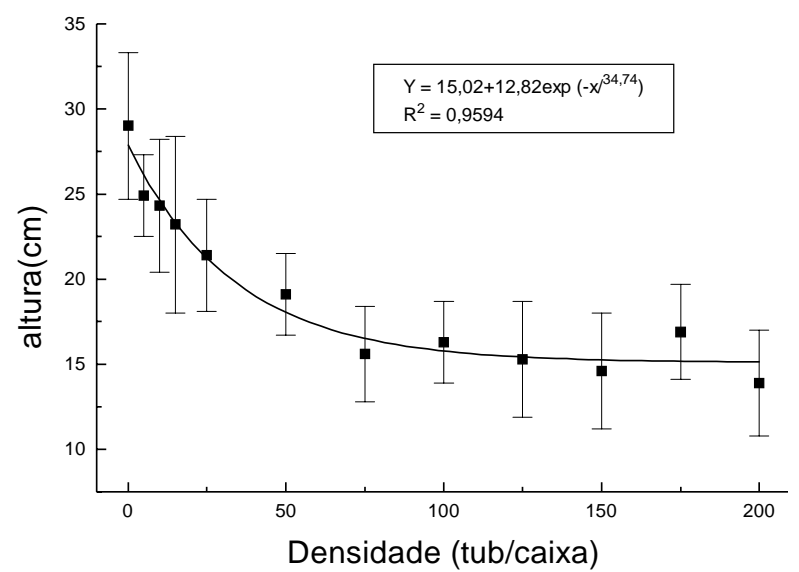

Figura 3 - Efeito da densidade de tubérculos de tiririca na altura das plantas de algodão aos 65 dias após a semeadura. Jaboticabal-SP, 2001.

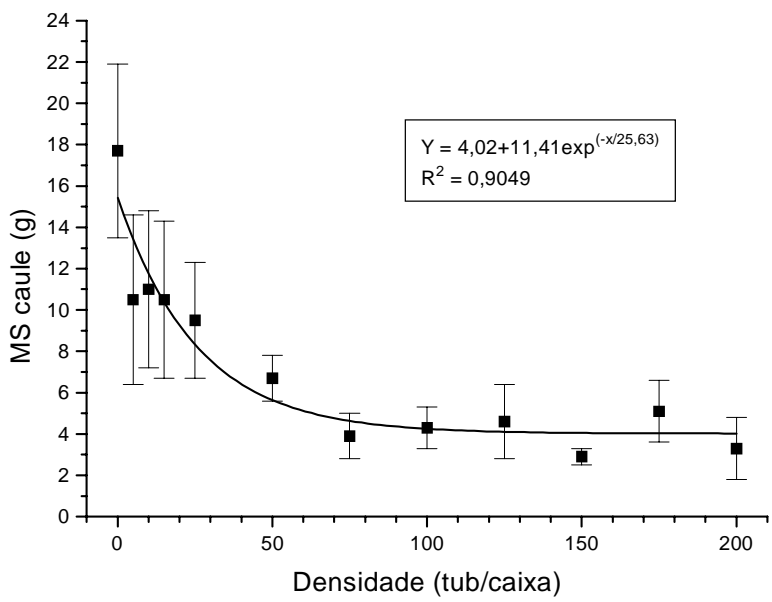

Figura 5 - Efeito da densidade de tubérculos de tiririca na matéria seca do caule das plantas de algodão aos 65 dias após a semeadura. Jaboticabal-SP, 2001.

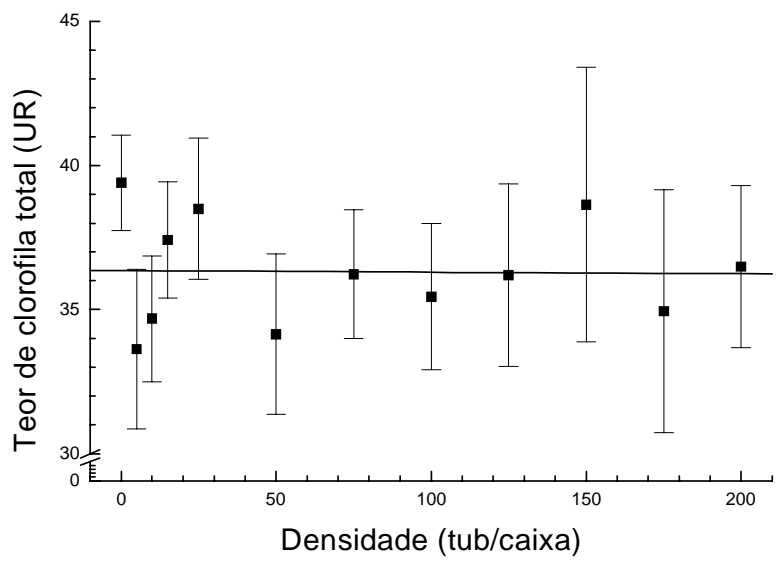

Figura 2 - Efeito da densidade de tubérculos de tiririca no teor relativo de clorofila total em folhas de algodão aos 50 dias após a semeadura. Jaboticabal-SP, 2001.

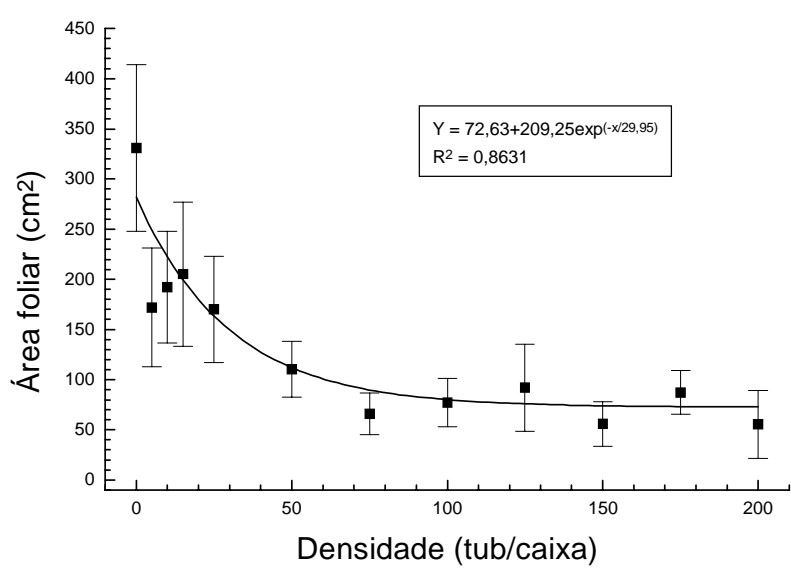

Figura 4 - Efeito da densidade de tubérculos de tiririca na área foliar das plantas de algodão aos 65 dias após a semeadura. Jaboticabal-SP, 2001.

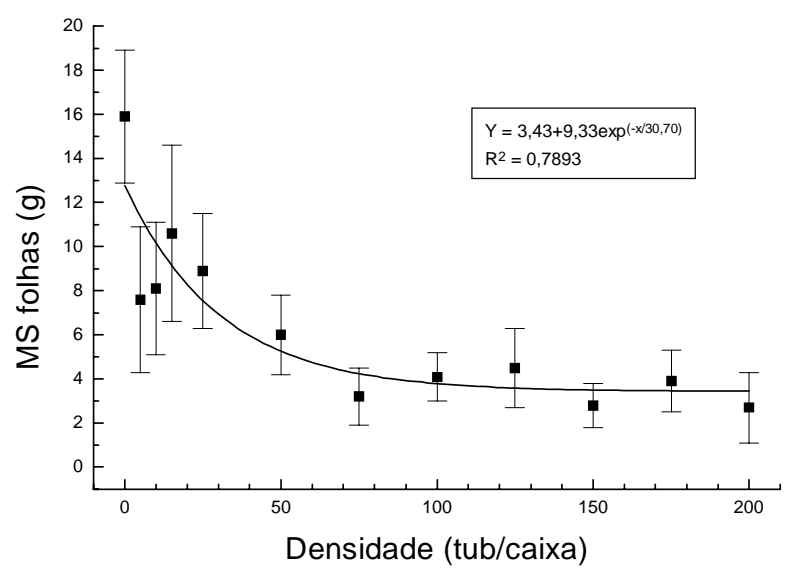

Figura 6 - Efeito da densidade de tubérculos de tiririca na matéria seca do caule das plantas de algodão aos 65 dias após a semeadura. Jaboticabal-SP, 2001.

Planta Daninha, Viçosa-MG, v.20, n.3, p.405-411, 2002 


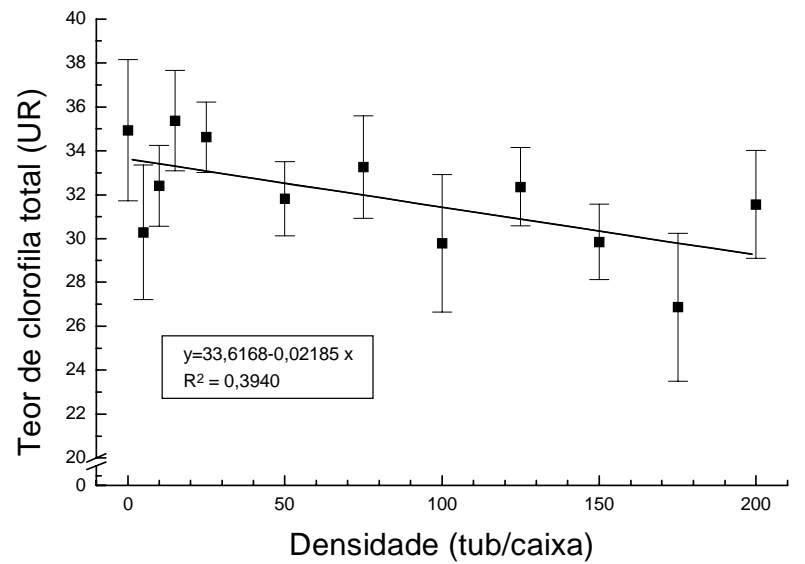

Figura 7 - Efeito da densidade de tubérculos de tiririca no teor relativo de clorofila total em folhas de algodão aos 65 dias após a semeadura. Jaboticabal-SP, 2001.

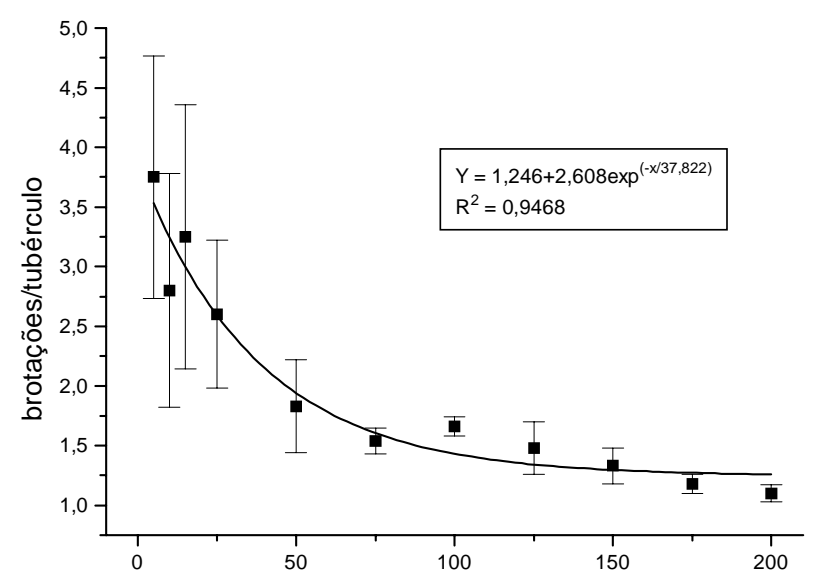

Figura 8 - Efeito da densidade de tubérculos de tiririca na taxa de brotações por tubérculo aos 65 dias após o plantio. Jaboticabal-SP, 2001.

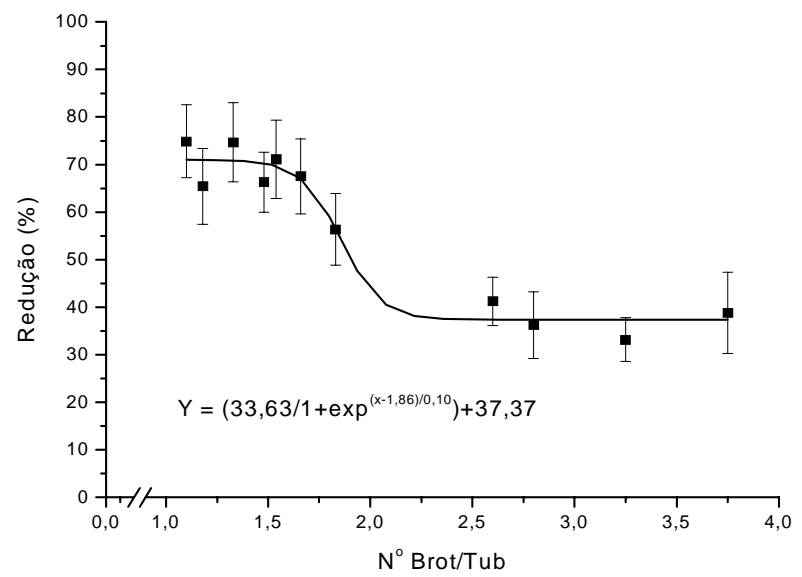

Figura 9 - Correlação entre o número de brotações por tubérculo e a redução porcentual observada em todas as características analisadas. Jaboticabal-SP, 2001.
Padronizando os efeitos da interferência da tiririca sobre as características avaliadas nas plantas de algodão (expressando-a por redução porcentual em relação à testemunha) e correlacionando-a com o número de brotações por tubérculo, obteve-se uma curva ajustada pelo modelo sigmoidal de Boltzman (Figura 9). Na interpretação desse modelo segundo Kuva et al. (2000), verifica-se que a redução máxima nos conjuntos de características analisadas foi de $71,0 \%$, enquanto a mínima foi de $37,4 \%$. Esse efeito de redução de $71,0 \%$ manteve-se praticamente constante de 1,1 a 1,6 brot/tub, após o qual decresceu acentuadamente, a uma taxa de $1,0 \%$ por 0,1 brot./tub., até atingir o valor de $37,4 \%$ de redução a partir de 2,2 brot./tub., com esse efeito mantendo-se constante até 3,7 brot./tub. Ainda de acordo com esse modelo matemático, em valores acima de 1,8 brot./ tub. os efeitos da interferência interespecífica da tiririca se amenizam, passando a predominar os efeitos da interferência intra-específica; esse valor-limite corresponde justamente à densidade de 75 tub./caixa.

De acordo com os resultados obtidos, observou-se que:

- A interferência de tiririca no crescimento inicial do algodão afetou negativamente todas as características analisadas.

- As características avaliadas nas plantas de algodão cv. Delta Opal mais sensiveis ao efeito dos tubérculos da tiririca foram: área foliar, massa seca de folhas e caule e altura das plantas, nessa ordem.

- A competição intra-específica na tiririca acentuou-se a partir de 75 tubérculos/caixa, quando se obteve mais do que 1,8 brotação por tubérculo.

\section{LITERATURA CITADA}

AGRIANUAL 2001: anuário da agricultura brasileira. São Paulo: FNP Consultoria \& Comércio, 2000. p. 153.

AZEVEDO, D. M. P. et al. Manejo de plantas daninhas no cultivo do algodoeiro herbáceo. Campina Grande: EMBRAPA-CNPA, 1993. 11 p. (Comunicado Técnico, $35)$.

BARARPOUR, M.T.; TALBERT, R.E.; FRANS, R.E. Spotted spurge interference with cotton (Gossypium hirsutum). Weed Sci., v. 42, n. 4, p. 553-555, 1994. 
BELTRÃO, N. E.; AZEVEDO, D. M. P. Controle de plantas daninhas na cultura do algodoeiro. Campina Grande: EMBRAPA-CNPA, 1994. 154 p.

BENEDICT, C. R. Physiology. In: KOHEL, R. J.; LEWIS, C. F. (Eds.). Cotton. Madison: Americam Society of Agronomy, 1984. p. 151-200.

BLANCO, H. G. A importância dos estudos ecológicos nos programas de controle de plantas daninhas. Biológico, v. 38, n. 10, p. 343-350, 1972.

BLANCO, H. G.; ARËVALO, R. A.; CHIBA, S. Convivência de populações de Cyperus rotundus L. com plantas de algodoeiro herbáceo. Pesq. Agropec. Bras., v. 26, n. 2, p. 169-176, 1991.

BLEASDALE, J. K. A. Studies on plant competition. In: HARPER, J.L. (Ed.). The biology of weeds. Oxford: Blackweel Scientific Publications, 1960. p. 133-142.

CHRISTOFFOLETI, P. J.; VICTORIA FILHO, R. Efeitos da densidade e proporção de plantas de milho (Zea mays L.) e caruru (Amaranthus retroflexus L.) em competição. Planta Daninha, v. 14, n. 1, p. 42-47, 1996.

CIA, E.; FREIRE, E. C.; SANTOS, W. J. (Eds). Cultura do algodoeiro. Piracicaba: POTAFOS, 1999. p. 101 e 157.

\section{EMPRESA BRASILEIRA DE PESQUISA}

AGROPECUÁRIA - EMBRAPA. Empresa Brasileira de Pesquisa Agropecuária. Serviço Nacional de Levantamento e Conservação de Solos. Sistema brasileiro de

classificação de solos. Rio de Janeiro, 1999. não paginado

FORSTER, R.; PAULO, E. M. Período de competição de populações de gramíneas e dicotiledôneas, vegetando em separado, na cultura do algodão. In: CONGRESSO BRASILEIRO DE HERBICIDAS E PLANTAS DANINHAS, 15., 1984, Belo Horizonte. Resumos... Belo Horizonte: SBCPD, 1984. p. 38.

FREIRE, E. C.; ALVES, E. J. Estudo do sistema radicular do algodoeiro em diferentes espaçamentos. In: FREIRE, E. C.; SOUZA, L. S. ; ALVES, E. J. Experimentação algodoeira nos Estados da Bahia e Sergipe, 1971/74. Salvador: EMBRAPA- Representação do Estado da Bahia, 1976. p. 81-86. (Comunicado Técnico, 1).
FRIEDMAN, T.; HOROWITS, M. Biologically active substances in subterranean parts of purple nutsedge. Weed Sci, v. 19, p. 398-401, 1971.

KEELEY, P. E.; THULLEN, R. J. Growth and interaction of bermudagrass (Cynodon dactylon) with cotton (Gossypium hirsutum). Weed Sci., v. 39, n. 4, p. 570-574, 1991.

KUVA, M. A. et al. Períodos de interferência das plantas daninhas na cultura de cana-de-açúcar. I - Tiririca. Planta Daninha, v. 18, n. 2, p. 241-252, 2000.

LACA-BUENDIA, J.P. Controle de plantas daninhas na cultura algodoeira. Inf. Agropec., v. 92, n. 8, p. 28-33, 1992.

MEISSNER, R.; NEL, P. C.; BEYERS, E. A. Preliminary studies on growth influencing effects of red nutgrass (Cyperus rotundus L.) on some crop plantas. Crop. Prod., v.6, p. 77-80, 1977.

MOFFETT, J. E.; McCLOSKEY, W. B. Effects of soil moisture and yellow nutsedge (Cyperus esculentus) density on cotton (Gossypium hirsutum). Weed Sci., v. 46, n. 2, p. 231-237, 1998.

MORGAN, G. D.; BAUMANN, P. A.; CHANDLER, J. M. Competitive impact of palmer amaranth (Amaranthus palmeri) on cotton (Gossypium hirsutum) development and yield. Weed Technol., v. 15, n. 3, p. 408-412, 2001.

OLIVEIRA, F. A.; SILVA, J. J. S. Uso consecutivo e desenvolvimento radicular do algodoeiro herbáceo (Gossypium hirsutum L.). Salvador: EPABA, 1987. 22 p. (Boletim de Pesquisa, 8).

PITELLI, R. A. Interferência das plantas daninhas em culturas agrícolas. Inf. Agropec., v. 11, n. 129, p. 16-27, 1985 .

RAIJ, B.van. et al. Recomendações de adubação e calagem para o Estado de São Paulo. Campinas: Instituto Agronômico/Fundação IAC, 1997. p. 109-111.

SOLOMON, M. E. Dinâmica de populações. São Paulo: E.P.V., p. 43-46, 1980.

VENCILL, W. K.; GIRAUTO, L. J.; LANGDALE, G. W. Response of cotton (Gossypium hirsutum) to costal bermudagrass (Cynodon dactylon) densiy in a no-tillage system. Weed Sci., v. 40, n. 3, p. 455-458-459, 1992. 